\title{
ПРОБЛЕМЫ АДМИНИСТРАТИВНОГО ПРОЦЕССА ПРИ ПРИМЕНЕНИИ ЗАКОНОДАТЕЛЬСТВА В СФЕРЕ ОБЪЕКТОВ КУЛЬТУРНОГО НАСЛЕДИЯ (НА ПРИМЕРЕ КРАСНОДАРСКОГО КРАЯ)
}

\begin{abstract}
Аннотация: В работе автором анализируется процедура совершения органами государственной власти, уполномоченными в срере объектов культурного наследия, отдельных действий (согласование проектов, выдача разрешения на проведение работ по сохранению, требование о проведении историко-культурной экспертизы, постановка на государственную охрану) и процедура обжалования указанных действий заинтересованными лицами. Выявляются существующие проблемы: процесса обжалования (судебная экспертиза), законодательства об объектах культурного наследия (в части регламентации процедуры совершения отдельных действий), компетенции уполномоченных органов (в т.ч. ее превышения). Общенаучные методы: от абстрактного к конкретному, индукции и дедукции, анализа и синтеза, сравнительно-правовой метод; системный метод. научная новизна проявляется: в самой постановке вопроса в данной области, проведении сравнительного анализа действующего законодательства и сложивщейся судебной и административной практики его применения, а так же в предлагаемых в результате решениях освещенных проблем: необходимости проведения судебных экспертиз по таким категориям дел, запрете подмены судом уполномоченного органа государственной власти, уменьшении перечня "усмотренческих" полномочий государственного органа, законодательном закреплении отдельных терминов.

Ключевые слова: объект культурного наследия, обжалование, административная процедура, усмотренческие полномочия, коррупционный фактор, историко-культурная экспертиза, работы по сохранению, включение в список, предмет охраны, ограничения/обременения.
\end{abstract}

$\mathrm{B}$ последнее десятилетие у ученых-административистов весьма популярной темой исследования и обсуждения является административная юстиция и административный процесс. Выдвигаются различные мнения и концепции относительно подходов к данному вопросу, предлагается реформирование действующей системы, в том числе, как с принятием новых комплексных процессуальных актов, так и созданием новых специально уполномоченных органов государственной власти. Указанное явление носит закономерный характер, так как является следствие целого ряда объективных факторов, и, как следствие, назревших практических проблем в данной сфере. И только выявление и комплексный анализ таких проблем и поможет найти приемлемый ответ и достигнуть консенсуса в данном вопросе.
В связи с этим, в рамках данной статьи, хотелось бы показать процессуальные особенности и проблемы рассмотрения дел, возникающих из административных и иных публичных правоотношений, в сфере объектов культурного наследия народов Российской Федерации. Это позволит уяснить как часто возникающие типичные (системные) проблемы, так и особенности, связанные именно со спецификой сферы «культура» и государственного управления в ней. Также это позволит выявить ряд проблем администрирования и эффективности существующего управления в данной сфере.

Итак, первым проблемным моментом, на который бы хотелось обратить внимание, является большое количество споров, связанных с фактом наличия статуса объекта культурного наследия и 
вытекающими из этого правовыми последствиями (ограничениями, обременениями, запретами).

В действующем Федеральном законе от 25 июня 2002 года № 73-Ф3 «Об объектах культурного наследия (памятниках истории и культуры) народов Российской Федерации» [1] (далее - Закон) достаточно подробно описывается порядок присвоения статуса объекта культурного наследия, а также вновь выявленного объекта культурного наследия. При этом устанавливается срок указанной процедуры - 1 (один) год с момента сбора всех документов на вновь выявленный объект культурного наследия. Учитывая, что среди необходимых документов имеются заключение историко-культурной экспертизы (оплачиваемой заинтересованной стороной - т.е. в большинстве случаев государственным органом; при ограниченном количестве экспертов - в Краснодарском крае лишь 2 человека), то как правило этот срок не соблюдается. Особое место здесь занимают объекты культурного наследия, которые были выявлены в период с июня 2002 года по август 2010 года, когда наконец были приняты необходимые нормативноправовые акты и появились первые аттестованные историко-культурные эксперты [2]. Не лучше обстоит дело и с объектами культурного наследия, которые выявлены еще с 1990-х годов (по старым правилам), но так и остаются в настоящее время в том же статусе. Более того, Законом предусмотрено наличие целого ряда обязательных документов, которые подтверждают статус объекта культурного наследия - паспорт, учетная карта, отчеты о разведках и раскопках, разделы обеспечения сохранности, проекты зон охраны и пр. Учитывая большое количество объектов культурного наследия и слабое финансирование этой сферы, такие документы далеко не всегда имеются.

Все это привело к тому, что физические и юридические лица, недовольные тем, что принадлежащие им объекты недвижимости имеют статус объекта культурного наследия, что, соответственно, порождает для них существенные ограничения в использовании таковых, начали обращаться в суд с заявлениями о признании незаконным и отмене решения государственного органа о присвоении статуса объекта культурного наследия (вновь выявленного объекта).

Так, например, 000 «Симон» обратилось в Арбитражный суд Краснодарского края (далее - АC КК) с заявлением о признании незаконным и отмене Распоряжения комитета по охране, реставрации и эксплуатации историко-культурных ценностей (наследия) Краснодарского края от 10.10.1995 г. № 14-р, которым в качестве вновь выявленного объекта культурного наследия признано, принадлежащее ему здание «Дом жилой, Корпус ватной фабрики братьев Тарасовых, 1980-е гг.». Решением суда первой инстанции заявление удовлетворено, распоряжение признано незаконным [3]. При этом одним из аргументов являлось нарушение процедуры проведения экспертизы, а вторым - недоказанная (сомнительная) историко-культурная ценность объекта. Также указывалось на отсутствие сведений о статусе объекта в технической (технический и кадастровый паспорта) и правоустанавливающей (свидетельство о государственной регистрации права) документации. Постановлением суда апелляционной инстанции, оставленным без изменения постановлением суда кассационной инстанции, указанное решение было отменено, в удовлетворении заявления отказано в полном объеме. Обоснование вновь принятого решения основывалось на тех же обстоятельствах, но рассмотренных «под новым углом». Было указано на возможность замены заключения экспертизы протоколом совещания лиц, имеющих специальные познания в данной области, в котором они высказывают мнение о возможности включения такого объекта в список вновь выявленных объектов культурного наследия, а так же на несомненную историко-культурную ценность объекта, отраженную в исторической справке, имеющейся в архивах государственного органа. Отсутствие же информации о статусе объекта в его технической и правоустанавливающей документации не является основанием для не признания его таковым, а влияет лишь на субъективную сторону в деяниях собственника.

По другому делу, гр-н Попандопуло В.В. обратился в Северский районный суд КК с заявлением о признании недействительными и отмене приказа управления по охране, реставрации и эксплуатации историко-культурных ценностей (наследия) Краснодарского края от 11.08.2008 г. № 63 и распоряжения комитета по охране, реставрации и эксплуатации историко-культурных ценностей (наследия) Краснодарского края от 21.05.1996 г. № 11-1-р, которыми расположенному на принадлежащем ему земельном участке объекту присвоен статус выявленного объекта культурного наследия «селище Вышка» [4]. Судом заявленные требования удовлетворены в полном объеме, указано на то, что у государственного органа отсутствуют документы, подтверждающие историко-культурную 
ценность объекта, нарушен порядок присвоения статуса выявленному объекту культурного наследия, в том числе - не сообщено собственнику об этом. При этом судом хотя и отражен в акте, но абсолютно не принят во внимание отчет о результатах археологических разведок, которым подтверждено наличие объекта культурного наследия.

Суд же Ханты-Мансийского автономного округа - Югры, в аналогичной ситуации, наоборот стал на сторону государственного органа, указывая на то, что наличие отчета об археологических разведках, проведенных в соответствии с предусмотренной законодательством РФ процедурой, является достаточным подтверждением наличия вновь выявленного объекта культурного наследия, утверждения границ его территории и использования, в связи с чем в удовлетворении заявления отказал [5].

Наглядным примером не учета статуса объекта культурного наследия, в связи с его спорностью, является серия судебных дел по заявлениям прокурора западного округа г. Краснодара о признании незаконными заключений государственной экспертизы проектной документации и разрешения на строительство, в связи с не отражением сведений о наличии объекта культурного наследия [6]. Суд, отказывая в удовлетворении заявленных требований, указал на то, что факт наличия объекта культурного наследия «Памятное место, где в 1917 г. размещался Екатеринодарский городской комитет большевиков» на спорном земельном участке не доказан, его историко-культурная ценность - не подтверждена, какая-либо учетная документация - отсутствует.

Прямо противоположным является целый ряд решений АC КК по заявлениям управления по охране, реставрации и эксплуатации историкокультурных ценностей (наследия) Краснодарского края (далее - Управление) к администрациям муниципальных образований Краснодарского края о признании недействительными постановлений об утверждении градостроительного планов земельного участка и признании незаконными выданных разрешений на строительство в связи с не учетом факта наличия на спорных земельных участках объектов культурного наследия [7].

Таким образом, мы видим, что суды при рассмотрении такой категории дел обращают внимание как на процессуальную сторону, так и на факт наличия или отсутствия историко-культурной ценности самого объекта - т.е. по существу вторгаются в компетенцию государственного органа, специально уполномоченного в данном вопросе. При- чем такая постановка вопроса характерна и для исковых заявлений, с которыми государственный орган обращается к физическим и юридическим лицами в данной сфере.

Например, АС КК было отказано в удовлетворении исковых требований департамента культуры Краснодарского края к ЗАО «Факел» о восстановлении памятника архитектуры именно на том основании, что истец не смог доказать какое именно из разрушенных зданий являлось объектом культурного наследия, какой историко-культурный интерес оно представляло и был ли объект культурного наследия вообще [8].

Из вышесказанного становится абсолютно очевидным, что при рассмотрении такой категории дел необходимо проводить судебную экспертизу, которая будет подтверждать или опровергать историко-культурную ценность объекта, имеющего статус объекта культурного наследия (выявленного объекта). Однако, в большинстве случаев таковая отсутствует, суды самостоятельно берут на себя ответственность по определению таковой исходя из имеющихся доказательств по делу. Ярким примером ошибочности такой позиции является постановление арбитражного суда апелляционной инстанции по делу № A32-18248/2012 [9]. В рамках указанного дела, судом первой инстанции, без проведения экспертизы, был удовлетворен иск администрации муниципального образования город Сочи к ЗАО «Санаторий «Кавказская Ривьера» о сносе самовольных построек. Однако, в ходе апелляционного производства была назначена судебная экспертиза, которая подтвердила доводы ответчика о том, что один из сносимых объектов является объектом культурного наследия, в связи с чем решение было изменено в части.

Следующим серьезным проблемным моментом административного процесса в сфере объектов культурного наследия, является наличие большого количества усмотрения (субъективности), как со стороны государственных органов (должностных лиц), так и со стороны судов. Объективной причиной данного обстоятельства является особенность самой сферы культуры, а также не эффективность института административных регламентов, что впрочем не устраняет необходимости выработки каких-либо единых схем для всех субъектов.

Так, например, в практике административных органов в сфере государственной охраны объектов культурного наследия присутствует такие термины, как визуальный облик объекта культурного наследия и его визуальное восприятие. Соответ- 
ственно, принимая какое-либо решение о вмешательстве в облик объекта (например: размещение рекламы или вывески на фасаде, сплит-системы и пр.) государственный орган исходит именно из них. В основу таких терминов кладутся положения Закона о недопустимости изменения предмета охраны объекта культурного наследия, а также ухудшения его состояния. Вместе с тем, предмет охраны для каждого объекта культурного наследия разрабатывается и утверждается отдельно в его учетной документации, а учитывая, что это требование появилось лишь в июне 2002 года, а начало реализовываться и того позже, то естественным является то обстоятельство, что предмет охраны утвержден едва ли для 30 \% памятников. Ухудшение же состояния объекта культурного наследия, так же весьма неоднозначное понятие, требующее подчас, сложных исследований (экспертизы).

Таким образом, на практике получается, что административный орган зачастую отказывает заявителям лишь на том основании, что в результате их действий будет нарушено визуальное восприятие облика памятника, что приведет к ухудшению его состояния. Заявителю предлагается самостоятельно за свой счет провести необходимые изыскания (посредством привлечения специализированных организаций) по этому поводу и обратиться вновь. Однако, результаты таких изысканий отнюдь не будут означать, что государственный орган согласится с ними в конечном итоге.

Так, например, решением АC КК было отказано $3 А О$ «Реал Эстейт-Руссия» в удовлетворении заявления к Управлению о признании отказа в согласовании размещения рекламной вывески незаконным и обязании выдать положительное заключение [10]. В обоснование судебного акта положены доводы о том, что рекламная вывеска нарушает визуальное восприятие здания-памятника, негативно сказывается на его состоянии. При этом в ходе судебного заседания, на соответствующее заключение заявителя, проведенное им по данному вопросу, было представлено заключение государственного органа и специализированной организации, подведомственной данному органу, с прямо противоположными выводами.

Вместе с тем, по другому делу, в аналогичной ситуации, Октябрьский районный суд города Краснодара указал на то, что действующим законодательством РФ не предусмотрено понятие «визуальное восприятие» объекта культурного наследия, в связи с чем оно не может быть положено в основу законного решения [11]. Относительно же заключений специализированных организаций по данному вопросу указано, что они являются заинтересованными лицами, так как подведомственны и подконтрольны государственному органу.

Другим примером усмотрения со стороны государственного органа является отказ в принятии и утверждении проектной документации при имеющемся положительном заключении государственной историко-культурной экспертизы. Так и Законом и Постановлением Правительства РФ от 15 июля 2009 года № 569 «Об утверждении Положения о государственной историко-культурной экспертизе» [12] установлены случаи необходимости таковой, а также все основания для несогласия государственного органа с ее заключением и его последующие действия.

Однако, на практике, государственный орган, не согласный с разработанной документацией и имеющимся заключением, либо заставляет устранять выявленные им замечания к проектной документации, что влечет и обязанность по прохождению вновь государственной историко-культурной экспертизы (так как меняется документация), либо отказывает, ссылаясь на то, что не согласен с заключением. В действующем законодательстве не предусмотрена обязанность государственного органа в таких случаях самостоятельно организовывать проведение повторной (независимой) историко-культурной экспертизы, что, естественно, порождает судебный спор, как единственный способ выхода из ситуации (если не брать в расчет коррупционные способы).

Также нередки и случаи избыточного требования на получение заключения такой экспертизы. Так, решением АС КК заявление 000 «Эстейт» к Управлению о признании незаконным отказа в согласовании устройства подвала и дополнительного входа в объект культурного наследия и обязании согласовать таковой, было удовлетворено в полном объеме [13]. Требования заявителя основывались на том, что им, посредством специализированной организации, была разработана проектная документация по устройству в объекте культурного наследия подвала и дополнительного входа в него. Это было обосновано, как историческими документами, указывающими, что ранее в этом месте уже был подвал (засыпан позже), так и требованиями органа государственного пожарного надзора. Административный орган посчитал, что такую документацию должна разрабатывать только лишь организация, имеющая лицензию на проведение работ по сохранению объекта культур- 
ного наследия, в порядке, предусмотренном для работ по сохранению (получение задания и разрешения в государственном органе), и на такую документацию должно быть получено заключение государственной историко-культурной экспертизы. Суд, принимая решение, указал, что работы по устройству подвала и входа в него, не являются работами по сохранению объекта культурного наследия, так как не затрагивают предмет охраны такового, в связи с чем требования государственного органа не обоснованы.

Необходимо отметить, что в практике деятельности государственных органов, уполномоченных в сфере объектов культурного наследия, часто встречаются такого рода требования, когда одно понятие подменяется другим (например: работы по подготовке проекта зон охраны вопреки Закону трактуются как работы по сохранению объекта культурного наследия, в связи с чем требуется не только лицензия, но и задание и разрешение на проведение работ). Безусловно это объясняется не только и не столько коррупционной составляющей, сколько разными трактовками положений Закона, а также заботой (а иногда и излишним рвением) о сохранении объектов культурного наследия.

По этим же причинам уполномоченным административным органом зачастую необоснованно возлагаются обязанности на физических и юридических лиц.

Так, решением АС КК были признаны незаконными предписания Кубанского управления Росохранкультуры, выданные в адрес 000 «Регион Рекрео Сервис» о необходимости разработки проекта зон охраны, переоформления охранного обязательства и акта технического состояния, получения паспорта объекта культурного наследия, проведения охранно-спасательных мероприятий на объекте культурного наследия и разработки проекта содержания и использования памятника, - как несоответствующие Закону [14]. Судом указано на отсутствие такой обязанности для данного лица в Законе, констатирован факт перекладывая государственным органом своей же обязанности на юридическое лицо.

В тесной связи с вышеуказанным основанием споров являются и случаи превышения органом его установленной компетенции.

Например, решением АС КК признано незаконным предписание Управления, выданное в адрес ЗАО «Санаторий «Кавказская Ривьера» об обязании воссоздать утраченный объект культурного наследия [15]. В судебном акте указано не только на отсутствие такой обязанности для собственника, но и на отсутствие полномочия по выдаче предписания с таким требованием у государственного органа (только в судебном порядке, но не административном).

Еще один часто встречающийся пример субъективных действий государственного органа в данной области, это выдача задания и разрешения на проведение работ по сохранению объекта культурного наследия. Без получения таковых, разработка проектной документации будет считаться незаконной. При обращении в государственный орган заявитель должен представить проект уже разработанного задания, а также прочие прилагающиеся документы (договор, лицензию, правоустанавливающие документы). А что делать, если государственный орган не согласен с проектом задания и теми мероприятиями, которые там запланированы. На практике это означает, что он просто не выдаст это задание в таком виде, а поменяет его. Однако, изменение задания - это изменение видов и состава работ, а следовательно - дополнительные денежные затраты и иной (нежели ожидаемый) результат. Также бывают случаи, когда уже разработанная и согласованная документация по каким-либо причинам перестает устраивать заказчика и ему необходимо разработать второй комплект такой документации, предусматривающей иные варианты решения, либо внести изменения в уже существующую проектную документацию (возможно со сменой подрядчика). Естественно необходимо вновь получать новое задание и разрешение, либо вносить изменения в действующее задание. Однако, государственный орган, считая это нецелесообразным или не устраивающим его по иным причинам (например не желает смены подрядной организации), отказывает в этом. Мотивация проста - нецелесообразно при имеющейся разработанной и утвержденной документации, нарушаются авторские права первоначального разработчика, изменение документации может привести к ухудшению состояния памятника. Именно так было мотивировано решение АС КК при рассмотрении заявления $3 \mathrm{AO}$ «Санаторий «Кавказская Ривьера» к Управлению о признании незаконным отказа в выдаче задания и разрешения на проведение проектных работ по сохранению объекта культурного наследия и обязании выдать их [16].

Необходимо отметить, что в силу положений Федерального закона от 27 июля 2010 года № 210-Ф3 «Об организации предоставления государственных и муниципальных услуг» [17] и иных 
нормативно-правовых актов, явившихся одним из следствий проведенной административной реформы, все государственные органы, в том числе и уполномоченные в сфере объектов культурного наследия, должны иметь административные регламенты предоставления той или иной услуги или исполнения государственной функции. Однако, указанные административные регламенты, могут включать в себя, как размытые формулировки (например: в предоставлении услуги может быть отказано в случае несоответствия действующему законодательству РФ), так и излишне детальные и трудновыполнимые (например: отрицательное заключение по размещению рекламы может быть выдано в случае ее несоответствия стилю, облику, цветовому решению памятника, несоответствия исторической среде, несоизмеримость пропорций, влияние на визуальное восприятие, возможное разрушение элементов декора или фасада) [18].

Судебная практика показывает, что при рассмотрении спора, суды, как правило, не обращают внимание на административные регламенты, а исследуют дело по существу. Все вышесказанное делает административные регламенты практически бесполезными с точки зрения эффективности государственного управления или защиты законных интересов физических и юридических лиц.

Приведенные в настоящей статьи примеры можно дополнять и дополнять, причем, диаметрально противоположными судебными актами по одним и тем же вопросам. Существует еще целый пласт практики в данной области, касающийся рассмотрения споров, связанных с землей, с оформлением охранных обязательств, с взысканием ущерба, привлечением к административной ответственности, порядком проведения мероприятий по государственному контролю и надзора и пр. Однако все они, по существу, сводятся к двум обозначенным выше моментам: возникновение споров из-за субъективности административного органа и разрешение спора с уходом от фактического предмета спора к исследованию существа явления и возможным предположениям о негативных последствиях, а также вопросах, которые выходят за пределы спора и компетенции суда. На лицо явное отсутствие единства судебной практики по целому ряду однотипных споров, а также разница в подходе при рассмотрении дел между судами общей юрисдикции и арбитражными судами.

Более того, в 2015 году вступает в силу очередной пакет изменений и дополнений в Закон, который существенно добавит количество адми- нистративных споров в данной сфере (чего только стоит новый порядок заключения охранных обязательств в одностороннем уведомительном порядке с определением мер, которые должен выполнять собственник/пользователь).

В связи с вышеизложенным, авторам видится, что необходимо либо на законодательном уровне (внесение изменений в соответствующий процессуальный документ), либо на уровне Верховного Суда РФ принять акт разъяснительного характера, который бы устанавливал для судов определенные ключевые моменты, подлежащие выяснению по таким категориям дел, пределы усмотрения суда и отступления от доводов сторон и предмета спора, обязательные процессуальные действия, (экспертиза, вызов специалиста и пр.), обязательный учет положений административных регламентов государственных органов. Это поможет выработать определенное единообразие при рассмотрении таких дел. Также видится необходимым на организационном уровне, в соответствующих судебных составах назначать конкретный круг судей, которые бы рассматривали такие дела. Это повысило бы качественный уровень принимаемых решений, так как судьи лучше владели бы данной сферой законодательства и сложившейся судебной практикой.

Что же касается второго фактора возникновения споров в данной области, то как мы видим административные регламенты в настоящее время не стали панацеей, что, по-видимому, связано с отсутствием реальной ответственности должностных лиц. И хотя уже неоднократно высказывалось мнение, что увеличением ответственности ничего не добьешься, вместе с тем на примере ужесточения административной ответственности в области дорожного движения и некоторых других сфер мы видим положительные результаты. Возможно, в рамках общей линии борьбы с коррупцией, установление конкретной ответственности должностных лиц за принятие незаконного и необоснованного решения - наилучший выход и не только для этой сферы. Например - предусмотреть соответствующий состав административного правонарушения в КоАП РФ с отягчающими признаками и разными видами административного наказания (вплоть до дисквалификации). Естественно такое решение должно быть строго обдуманным и четко регламентированным, что бы не сделать из него средство борьбы с должностными лицами уполномоченных органов государственной власти для «жуликоватых граждан». 


\section{Библиография:}

1. Об объектах культурного наследия (памятниках истории и культуры) народов Российской Федерации : Федеральный закон от 25 июня 2002 г. № 73-ФЗ (в ред. от 23 июля 2013 г. № 245-Ф3) // Собр. законодательства Рос. Федерации. - 2002. - № 26. - Ст. 2519; 2013. - № 30 (часть 1). - Ст. 4078.

2. Об утверждении Положения о порядке аттестации экспертов по проведению государственной историко-культурной экспертизы : приказ Министерства культуры РФ от 26 августа 2010 года № 563 (в ред. от 17 октября 2011 г. № 1003) // Российская газета. - 2010. - № 246; Бюллетень нормативных актов федеральных органов исполнительной власти. - 2011.-№ 49.

3. Решение Арбитражного суда Краснодарского края от 8 июля 2009 года по делу № А32-7328/2009-63/171 // Размещено на официальном сайте Высшего Арбитражного суда РФ. URL.: www.kad.arbitr.ru.

4. Решение Северского районного суда Краснодарского края от 15 июля 2014 года по делу № 2-1156/14 // Размещено на официальном сайте Краснодарского краевого суда. URL.: www.kubansud.ru.

5. Определение Верховного Суда РФ от 4 декабря 2013 года по делу № 69-АПГ13-5 // Размещено на официальном сайте Верховного Суда РФ. URL.: www.vsrf.ru.

6. Решение Октябрьского районного суда г.Краснодара от 19 сентября 2013 года по заявлению прокурора Западного округа г.Краснодара к ГАУ КК «Краснодаркрайгосэкспертиза»; решение Первомайского районного суда г.Краснодара от 15 июля 2013 года по заявлению прокурора Западного округа г.Краснодара к департаменту архитектуры и градостроительства м.о. г.Краснодар // Размещены на официальном сайте Краснодарского краевого суда. URL.: www.kubansud.ru.

7. Решение Арбитражного суда Краснодарского края от 25 сентября 2008 года по делу № A32-6680/2008-39/132; Решение Арбитражного суда Краснодарского края от 17 ноября 2009 года № А32-21579/2008-5/295; Решение Арбитражного суда Краснодарского края от 17 марта 2010 года по делу № A32-55816/2009-63/1023 и пр. // Размещено на официальном сайте Высшего Арбитражного суда РФ. URL.: www.kad.arbitr.ru.

8. Решение Арбитражного суда Краснодарского края от 31 января 2007 года по делу № A32-8172/2006-50/1 // Размещено на официальном сайте Высшего Арбитражного суда PФ. URL.: www.kad.arbitr.ru.

9. Постановление Пятнадцатого апелляционного суда от 15 июля 2013 года по делу № A32-18248/2012 // Размещено на официальном сайте Высшего Арбитражного суда РФ. URL.: www.kad.arbitr.ru.

10. Решение Арбитражного суда Краснодарского края от 22 декабря 2012 года по делу № A32-21193/2012 // Размещено на официальном сайте Высшего Арбитражного суда РФ. URL.: www.kad.arbitr.ru.

11. Решение Октябрьского районного суда г.Краснодара от 24 июня 2014 года по иску гр-ки Петренко Г.В. к гр-ну Трофимовскому А.И., ИП Шамша Э.П., ИП Елизаровой И.Ю. о демонтаже вывески // Размещено на официальном сайте Краснодарского краевого суда. URL.: www.kubansud.ru.

12. Об утверждении Положения о государственной историко-культурной экспертизе : Постановление Правительства РФ от 15 июля 2009 года № 569 ( в ред. от 4 сентября 2012 г. № 880) // Собр. законодательства Рос. Федерации. - 2009. - № 30. - Ст. 3812; 2012. - № 37. - Ст. 5000.

13. Решение Арбитражного суда Краснодарского края от 15 августа 2012 года по делу № A32-17829/2011 // Размещено на официальном сайте Высшего Арбитражного суда РФ. URL.: www.kad.arbitr.ru.

14. Решение Арбитражного суда Краснодарского края от 18 мая 2011 года по делу № А32-25849/2010 // Размещено на официальном сайте Высшего Арбитражного суда PФ. URL.: www.kad.arbitr.ru.

15. Решение Арбитражного суда Краснодарского края от 2 февраля 2011 года по делу № A32-31326/2010-36/753 // Размещено на официальном сайте Высшего Арбитражного суда РФ. URL.: www.kad.arbitr.ru.

16. Решение Арбитражного суда Краснодарского края от 19 сентября 2011 года по делу № A32-37144/10 // Размещено на официальном сайте Высшего Арбитражного суда PФ. URL.: www.kad.arbitr.ru.

17. Об организации предоставления государственных и муниципальных услуг : Федеральный закон от 27 июля 2010 года № 210-Ф3 (в ред. от 21.07.2014 г. № 263-Ф3) // Собр. законодательства Рос. Федерации. - 2010 . - № 31. - Ст. 4179; 2014. - № 30 (Часть 1). - Ст. 4264.

18. б утверждении административных регламентов управления государственной охраны объектов культурного наследия Краснодарского края «Согласование размещения и (или) установки, а также эксплуатации рекламных конструкций, афиш, вывесок, телевизионных антенн, электрических и телефонных кабелей, вентиляционных систем и иного оборудования в отношении объектов культурного наследия» : приказ управления по охране, реставрации и эксплуатации историко-культурных ценностей (наследия) Краснодарского края от 24.05 .2012 г. № 50 // Размещен на официальном сайте органа. URL.: uorn.krasnodar.ru.

\section{References (transliterated)}

1. Ob ob"ektakh kul'turnogo naslediya (pamyatnikakh istorii i kul'tury) narodov Rossiiskoi Federatsii : Federal'nyi zakon ot 25 iyunya 2002 g. № 73-FZ (v red. ot 23 iyulya 2013 g. № 245-FZ) // Sobr. zakonodatel'stva Ros. Federatsii. - 2002. № 26. - St. 2519; 2013. - № 30 (chast' 1). - St. 4078. 
Административное и муниципальное право $1(85) \cdot 2015$

2. Ob utverzhdenii Polozheniya o poryadke attestatsii ekspertov po provedeniyu gosudarstvennoi istoriko-kul'turnoi ekspertizy : prikaz Ministerstva kul'tury RF ot 26 avgusta 2010 goda № 563 (v red. ot 17 oktyabrya 2011 g. № 1003) // Rossiiskaya gazeta. 2010. - № 246; Byulleten' normativnykh aktov federal'nykh organov ispolnitel'noi vlasti. - 2011.-№ 49.

3. Reshenie Arbitrazhnogo suda Krasnodarskogo kraya ot 8 iyulya 2009 goda po delu № A32-7328/2009-63/171 // Razmeshcheno na ofitsial'nom saite Vysshego Arbitrazhnogo suda RF. URL.: www.kad.arbitr.ru.

4. Reshenie Severskogo raionnogo suda Krasnodarskogo kraya ot 15 iyulya 2014 goda po delu № 2-1156/14 // Razmeshcheno na ofitsial'nom saite Krasnodarskogo kraevogo suda. URL.: www.kubansud.ru.

5. Opredelenie Verkhovnogo Suda RF ot 4 dekabrya 2013 goda po delu № 69-APG13-5 // Razmeshcheno na ofitsial'nom saite Verkhovnogo Suda RF. URL.: www.vsrf.ru.

6. Reshenie Oktyabr'skogo raionnogo suda g.Krasnodara ot 19 sentyabrya 2013 goda po zayavleniyu prokurora Zapadnogo okruga g.Krasnodara k GAU KK «Krasnodarkraigosekspertiza»; reshenie Pervomaiskogo raionnogo suda g.Krasnodara ot 15 iyulya 2013 goda po zayavleniyu prokurora Zapadnogo okruga g.Krasnodara k departamentu arkhitektury i gradostroitel'stva m.o. g.Krasnodar // Razmeshcheny na ofitsial'nom saite Krasnodarskogo kraevogo suda. URL.: www. kubansud.ru.

7. Reshenie Arbitrazhnogo suda Krasnodarskogo kraya ot 25 sentyabrya 2008 goda po delu № A32-6680/2008-39/132; Reshenie Arbitrazhnogo suda Krasnodarskogo kraya ot 17 noyabrya 2009 goda № A32-21579/2008-5/295; Reshenie Arbitrazhnogo suda Krasnodarskogo kraya ot 17 marta 2010 goda po delu № A32-55816/2009-63/1023 i pr. // Razmeshcheno na ofitsial'nom saite Vysshego Arbitrazhnogo suda RF. URL.: www.kad.arbitr.ru.

8. Reshenie Arbitrazhnogo suda Krasnodarskogo kraya ot 31 yanvarya 2007 goda po delu № A32-8172/2006-50/1 // Razmeshcheno na ofitsial'nom saite Vysshego Arbitrazhnogo suda RF. URL.: www.kad.arbitr.ru.

9. Postanovlenie Pyatnadtsatogo apellyatsionnogo suda ot 15 iyulya 2013 goda po delu № A32-18248/2012 // Razmeshcheno na ofitsial'nom saite Vysshego Arbitrazhnogo suda RF. URL.: www.kad.arbitr.ru.

10. Reshenie Arbitrazhnogo suda Krasnodarskogo kraya ot 22 dekabrya 2012 goda po delu № A32-21193/2012 // Razmeshcheno na ofitsial'nom saite Vysshego Arbitrazhnogo suda RF. URL.: www.kad.arbitr.ru.

11. Reshenie Oktyabr'skogo raionnogo suda g.Krasnodara ot 24 iyunya 2014 goda po isku gr-ki Petrenko G.V. k gr-nu Trofimovskomu A.I., IP Shamsha E.P., IP Elizarovoi I.Yu. o demontazhe vyveski // Razmeshcheno na ofitsial'nom saite Krasnodarskogo kraevogo suda. URL.: www.kubansud.ru.

12. Ob utverzhdenii Polozheniya o gosudarstvennoi istoriko-kul'turnoi ekspertize : Postanovlenie Pravitel'stva RF ot 15 iyulya 2009 goda № 569 ( v red. ot 4 sentyabrya 2012 g. № 880) // Sobr. zakonodatel'stva Ros. Federatsii. - 2009. - № 30. - St. 3812; 2012. - № 37. - St. 5000.

13. Reshenie Arbitrazhnogo suda Krasnodarskogo kraya ot 15 avgusta 2012 goda po delu № A32-17829/2011 // Razmeshcheno na ofitsial'nom saite Vysshego Arbitrazhnogo suda RF. URL.: www.kad.arbitr.ru.

14. Reshenie Arbitrazhnogo suda Krasnodarskogo kraya ot 18 maya 2011 goda po delu № A32-25849/2010 // Razmeshcheno na ofitsial'nom saite Vysshego Arbitrazhnogo suda RF. URL.: www.kad.arbitr.ru.

15. Reshenie Arbitrazhnogo suda Krasnodarskogo kraya ot 2 fevralya 2011 goda po delu № A32-31326/2010-36/753 // Razmeshcheno na ofitsial'nom saite Vysshego Arbitrazhnogo suda RF. URL.: www.kad.arbitr.ru.

16. Reshenie Arbitrazhnogo suda Krasnodarskogo kraya ot 19 sentyabrya 2011 goda po delu № A32-37144/10 // Razmeshcheno na ofitsial'nom saite Vysshego Arbitrazhnogo suda RF. URL.: www.kad.arbitr.ru.

17. Ob organizatsii predostavleniya gosudarstvennykh i munitsipal'nykh uslug : Federal'nyi zakon ot 27 iyulya 2010 goda № 210-FZ (v red. ot 21.07.2014 g. № 263-FZ) // Sobr. zakonodatel'stva Ros. Federatsii. - 2010 . - № 31. - St. 4179; 2014 . - № 30 (Chast' 1). - St. 4264.

18. Ob utverzhdenii administrativnykh reglamentov upravleniya gosudarstvennoi okhrany ob"ektov kul'turnogo naslediya Krasnodarskogo kraya «Soglasovanie razmeshcheniya i (ili) ustanovki, a takzhe ekspluatatsii reklamnykh konstruktsii, afish, vyvesok, televizionnykh antenn, elektricheskikh i telefonnykh kabelei, ventilyatsionnykh sistem i inogo oborudovaniya v otnoshenii ob"ektov kul'turnogo naslediya» : prikaz upravleniya po okhrane, restavratsii i ekspluatatsii istoriko-kul'turnykh tsennostei (naslediya) Krasnodarskogo kraya ot 24.05.2012 g. № 50 // Razmeshchen na ofitsial'nom saite organa. URL.: uorn.krasnodar.ru. 